\title{
Expression of "brown-in-white" adipocyte biomarkers shows gender differences and the influence of early dietary exposure
}

\author{
María Servera $\cdot$ Nora López $\cdot$ Francisca Serra $\cdot$ \\ Andreu Palou
}

Received: 30 May 2013/ Accepted: 8 November 2013/Published online: 30 November 2013

(C) Springer-Verlag Berlin Heidelberg 2013

\begin{abstract}
Induction of brown-like adipocytes (brite) in white adipose tissues may allow the conversion of lipid storage cells in fat-burning cells. Little is known concerning browning potential in males compared with females. In this study, we aimed to analyse whether gender differences were present in gene expression of "brite" markers as well as the impact of dietary manipulation at both early stages and adulthood in rats. We have determined the expression of brite markers and genes associated with lipid and energy metabolism in inguinal adipose tissue in adult male and female rats. We have analysed the impact of high-fat (HF) diet in adult life and of early leucine supplementation ( $2 \%$ ) during lactation. Results show that although both genders have the potential to induce brite genes in inguinal adipose tissue, males expressed higher levels (CIDEA, HOXC9 and SHOX2), which would imply a higher browning capacity in comparison with females. Minor impact of HF diet in adult life was observed in most of the genes studied. Interestingly, results showed that early Leu was able to compromise the metabolic fate of white and brite adipocytes later in adult life. Leucine supplementation programmed higher expression of cell death-inducing DFFA-like effector, accompanied with induction of sterol regulatory element binding transcription 1c factor and lower UPC2 expression, particularly in
\end{abstract}

Electronic supplementary material The online version of this article (doi:10.1007/s12263-013-0372-4) contains supplementary material, which is available to authorized users.

M. Servera $\cdot$ N. López $\cdot$ F. Serra $(\bowtie) \cdot$ A. Palou

Laboratory of Molecular Biology, Nutrition and Biotechnology (Nutrigenomics), University of the Balearic Islands (UIB) and CIBER Fisiopatología de la Obesidad y Nutrición (CIBEROBN), Palma de Mallorca, Spain

e-mail: francisca.serra@uib.es females. In addition, Leucine supplementation was associated with higher expression of leptin and PPAR $\gamma$ and decreased carnitine palmitoyl transferase in both genders. Although the exact role of these adaptations needs further comprehensive analysis, dietary Leu supplementation at early age programmed inguinal adipose tissue in a gender specific manner.

Keywords Brite biomarkers - Obesity - Leucine supplementation · Gender dimorphism

\section{Introduction}

Adipose tissue of mammals is integrated by at least two types of adipocytes, white and brown, which are organized in white (WAT) and brown (BAT) adipose tissues constituting a multidepot organ called the adipose organ (Cinti 2005). This is a major endocrine organ exerting a profound influence on whole-body homoeostasis and body weight control (Saely et al. 2012). Both type of adipocytes share the property of accumulation and release of fatty acids, and they both express the rather specific adrenergic receptor $\beta 3$ (Richard and Picard 2011). However, they have distinct anatomy and function: white adipocytes are unilocular and regulate energy balance through secretion of leptin, while brown adipocytes are multilocular and rich in mitochondria and contribute to regulation of energy expenditure by means of uncoupling protein 1 (UCP1) protein, responsible for the heat production of these cells (Cinti 2005).

WAT and BAT are normally localized in anatomically distinct areas, although the presence of brown adipocytes expressing UCP1 in typical white fat pads also occurs under certain conditions (Cousin et al. 1992; Virtanen et al. 2009). Recently, molecular characterization of WAT has 
revealed the possibility of inducing a "browning process" in response to appropriate stimuli, like activation of $\beta$ adrenergic receptor (Ghorbani and Himms-Hagen 1997), long-term exposure to cold (Barbatelli et al. 2010), drugs (Distel et al. 2012) or even nutritional agents (Bonet et al. 2013). The mechanism of this plasticity is yet unknown and is under extensive investigation. These novel thermogenic brown-like adipocytes are also called "brite" (brown-inwhite) cells, are energy-expending cells found among energy-storing adipocytes and share characteristics with classical brown adipocytes (like the capacity for uncoupled respiration) and are developed in the post-natal period and are susceptible of activation by cold exposure or PPAR $\gamma$ agonists (Sharp et al. 2012).

In adult humans, novel imaging techniques have demonstrated the existence of active brown adipose tissue, which is acutely induced by cold and stimulated via the sympathetic nervous system (Nedergaard et al. 2007; Saito 2013). Furthermore, patients affected by pheochromocytoma secrete huge amounts of catecholamines and show high levels of active BAT by adrenergic stimulation (Frontini et al. 2013). Feasibility of browning process either by transdifferentiation (white adipocytes converted to brown) and/or by induction of novel brown/brite adipocytes in humans may provide an important strategy in obesity treatment, as these cells may contribute to attenuate the tendency to increase fat deposition seen in mice (Lasar et al. 2013).

Sex differences associated with fat distribution and correlations to metabolic health in humans are well established. Studies on morphological and metabolic properties of adipocytes, as well as on proliferation and differentiation potential of pre-adipocytes derived from different depots, with the purpose of understanding the intrinsic gender-specific metabolism have been performed (Karastergiou et al. 2012). However, little is known concerning gender differences in the metabolism of brite adipocytes and the changes occurring at gene expression level in the browning process in males and females. In this study, we aimed to analyse whether gender differences were present in gene expression of "brite" markers as well as the impact of dietary manipulation at both early stage (maternal supplementation with leucine) and adulthood (high-fat diet) in rats.

\section{Materials and methods}

\section{Experimental animals}

Animals were submitted to two dietary treatments: maternal leucine supplementation during lactation (L) and highfat (HF) diet at adulthood. L group was obtained by feeding

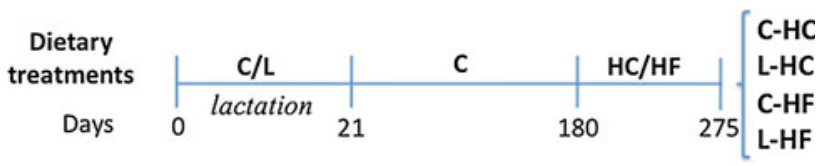

Fig. 1 Diagram representing the experimental design and diets. $C$ fed with chow diet, $L$ chow diet supplemented with $2 \%$ L-Leucine, $H C$ high carbohydrate diet and $H F$ high-fat diet

powder standard diet (1.11\% Leu) supplemented with $2 \%$ L-Leucine ( $>99 \%$ NT, Sigma-Aldrich, Madrid, Spain) from day 1 after delivery until weaning at 21 days of age (López et al. 2010). Control animals (C) were treated in the same conditions but fed with the non-supplemented powder standard diet. Then, offspring were caged by gender-mated animals and fed with standard diet. At the age of 6 months, both $\mathrm{L}$ and $\mathrm{C}$ animals were distributed into two dietary regimes, receiving either a high carbohydrate (HC) (3.85 kcal/g, $10 \%$ calories from fat, Ref D12450B) or a HF diet (4.73 kcal/g, $45 \%$ calories from fat, Ref D12451) [Research Diets (NJ, USA)]. A total of 8 experimental groups were followed ( $n=6$ each) according to diet (HC or $\mathrm{HF}$ ), early treatment (C or L) and sex (males, females). At the age of 9 months (275 days), animals were killed and adipose samples collected. The inguinal depot was rapidly removed, weighed, frozen in liquid nitrogen and stored at $-80{ }^{\circ} \mathrm{C}$. Diagram of the experimental dietary design is shown in Fig. 1.

The animal protocol followed in this study was reviewed and approved by the Committee of our University. All institutional and national guidelines for the use and care of laboratory animals were followed.

\section{RNA extraction}

Total RNA was extracted from the inguinal adipose depot by Tripure Reagent (Roche Diagnostic, Mannheim, Germany) according to the manufacturer's instructions. Final RNA precipitation was performed with $3 \mathrm{M}$ sodium acetate. Isolated RNA was quantified using a NanoDrop ND1000 spectrophotometer (NanoDrop Technologies, Wilmington, DE, USA) and its integrity confirmed by agarose gel electrophoresis.

Real-time quantitative polymerase chain reaction analysis

Real-time polymerase chain reaction (PCR) was used to measure mRNA expression levels of selected markers of brite, brown and white adipocytes. Guanosine diphosphate dissociation inhibitor (GDI) was used as reference gene; $0.08 \mu \mathrm{g}$ of total RNA (in a final volume of $5 \mu \mathrm{l}$ ) was denatured at $90{ }^{\circ} \mathrm{C}$ for $1 \mathrm{~min}$ and then reverse transcribed to cDNA using MuLV reverse transciptase (Applied 
Table 1 Nucleotide sequences of primers

\begin{tabular}{|c|c|c|c|}
\hline Gene $^{a}$ & Forward primer $\left(5^{\prime}-3^{\prime}\right)$ & Reverse primer $\left(5^{\prime}-3^{\prime}\right)$ & Amplicon size (bp) \\
\hline AdipoQ & GCTCAGGATGCTACTGTTG & TCTCACCCTTAGGACCAAG & 241 \\
\hline ATGL & TGTGGCCTCATTCCTCCTAC & AGCCCTGTTTGCACATCTCT & 271 \\
\hline CD36 & GTCCTGGCTGTGTTTGGA & GCTCAAAGATGGCTCCATTG & 319 \\
\hline CIDEA & TCAGACCCTAAGAGACAACACA & CATTGAGACAGCCGAGGA & 164 \\
\hline CPT1 & GCAAACTGGACCGAGAAGAG & CCTTGAAGAAGCGACCTTTG & 180 \\
\hline FASN & CGGCGAGTCTATGCCACTAT & ACACAGGGACCGAGTAAT & 222 \\
\hline GDI & CCGCACAAGGCAAATACATC & GACTCTCTGAACCGTCATCAA & 159 \\
\hline GLUT4 & GGCATGCGTTTCCAGTATGT & GCCCCTCAGTCATTCTCATC & 233 \\
\hline HOXC9 & CGGCAGCAAGCACAAAGA & AGAAACTCCTTCTCCAGTTCCA & 138 \\
\hline LEP & TTCACACACGCAGTCGGTAT & AGGTCTCGCAGGTTCTCCAG & 186 \\
\hline LPL & TATGGCACAGTGGCTGAAAG & CTGACCAGCGGAAGTAGGAG & 157 \\
\hline $\operatorname{PPAR} \gamma 2$ & GATCCTCCTGTTGACCCAGA & TCAAAGGAATGGGAGTGGTC & 164 \\
\hline RETN & СТССТССТTТТССТтТТСТТСС & TAGTGACGGTTGTGCCTTCT & 205 \\
\hline SCD2 & TTTCTCATCATCGCCAACAC & CTTTCCGCCCTTCTCTTTG & 189 \\
\hline SHOX2 & GCTGACGGAGGTGTCCCCTGA & CGAAAAGCCTCTCCAGCTCGTT & 143 \\
\hline SREBP1c & СССАСССССТТАСАСАСС & GCCTGCGGTCTTCATTGT & 198 \\
\hline TBx 15 & GGATGAGACAGGTGGTCAGTT & CACAGGCACAGGTT & 164 \\
\hline $\mathrm{UCP} 2$ & GGTCGGAGATACCAGAGCAC & ATGAGGTTGGCTTTCAGGAG & 174 \\
\hline XBP1 & TCCGCAGCACTCAGACTATGT & ATGCCCAAAAGGATATCAGACTC & 129 \\
\hline
\end{tabular}

ATGL adipose triglyceride lipase, CD36 cluster of differentiation 36, CIDEA cell death-inducing DFFA-Like Effector A, CPT1 carnitine palmitoyltransferase, FASN fatty acid synthase, GDI guanosine diphosphate dissociation inhibitor, GLUT4 facilitated glucose transporter 4, HOXC9 homeobox C9, LEP leptin, $L P L$ lipoprotein lipase, $P P A R \gamma 2$ peroxisome proliferator activated receptor gamma 2, RETN resistin, $S C D 2$ stearoyl-Coenzyme A desaturase 2, SHOX2 short stature homeobox 2, SREBP1c sterol regulatory element binding transcription factor 1c, TBx15 T-box $15, U C P 2$ uncoupling protein $2, X B P$ X-box binding protein 1

a Adipoq, adiponectin

Biosystem, Madrid, Spain) at $42{ }^{\circ} \mathrm{C}$ for $60 \mathrm{~min}$ and $99{ }^{\circ} \mathrm{C}$ for 5 min in an Applied Biosystems 2720 Thermal Cycler (Applied Biosystem, Madrid, Spain). Each PCR was performed in diluted (1/5) cDNA template, forward and reverse primers $(10 \mu \mathrm{M}$ each) and Power SYBER Green PCR Master Mix (Applied Biosystem, CA, USA). Primers were obtained from Sigma Genosys (Sigma-Aldrich Química, Madrid, Spain), and sequences are described in Table 1. Real-time PCR was performed using StepOnePlus Real-Time PCR System (Applied Biosystems) with the following profile: $10 \mathrm{~min}$ at $95^{\circ} \mathrm{C}$, followed by a total of 40 two-temperature cycles $\left(15 \mathrm{~s}\right.$ at $95{ }^{\circ} \mathrm{C}$ and $1 \mathrm{~min}$ at $\left.60{ }^{\circ} \mathrm{C}\right)$. In order to verify the purity of the products, a melting curve was produced after each run according to the manufacturer's instructions. The threshold cycle $(\mathrm{Ct})$ was calculated by the instrument's software (StepOne Software v2.2), and the relative expression of each mRNA was calculated using the $2^{-\Delta \Delta \mathrm{Ct}}$ method (Livak and Schmittgen 2001) corrected by the expression of GDI in the sample.

GDI was selected in front of $18 \mathrm{~S}$ gene because it was the most homogeneous between samples and, in addition, appearing with a $\mathrm{Ct}$ closer to most of the other genes analysed. Ct values of GDI were not different in control males from that of control females (both under C-HC groups) $[31.9 \pm 0.63$ and $30.3 \pm 0.65(p=0.10)$, in males and females, respectively]. In addition, the rest of potential comparisons of $\mathrm{Ct}$ values, under the same condition, between males and females were not statistically different [for example, C-HF groups gave a Ct value of $30.9 \pm 0.42$ in males and of $30.8 \pm 0.31$ in females $(p=0.99)$ ]. Therefore, we assumed that GDI expression was a valid housekeeping and useful for gender comparison (See supplementary information regarding selection of housekeeping gene). Data are presented as percentage of the values found in male control rats under $\mathrm{HC}$ diet $(\mathrm{C}-\mathrm{HC})$.

Western blot analysis of CIDEA

Inguinal samples were homogenized at $4{ }^{\circ} \mathrm{C}$ in RIPA buffer $(1: 3 \mathrm{wt} / \mathrm{vol})$. The homogenate was diluted for BCA Protein assay (Ref 23,225; Thermo Scientific, IL, USA). The proteins $(50 \mu \mathrm{g})$ were boiled in Laemmli sample buffer containing $5 \%$ 2-mercaptoethanol. After $2 \mathrm{~min}$ boiling, total protein was fractionated by the $4-15 \%$ precast polyacrylamide gel CriterionTM TGXTM (Ref 567-1084; Bio-Rad, Madrid, Spain) and electrotransferred 
onto a nitrocellulose membrane (Bio-Rad, Madrid, Spain). After blocking, the membrane was incubated with the primary rabbit polyclonal anti-rat-CIDEA-Rb antibody mapped to the C-terminal region of the receptor (Ref C7977, diluted 1:500; Sigma, Madrid, Spain) followed by the incubation with the infrared (IR)-dyed secondary goat anti-rabbit immunoglobulin G antibody (Ref 926-32211, diluted 1:20,000; LI-COR, NE, USA) and band identification and quantitation. Then, to detect $\beta$-actin, a stripping was performed (stripping buffer Ref: 928-40030, LI-COR, NE, USA) and the membrane was incubated with the primary mouse monoclonal anti-rat- $\beta$-actin (Ref 3700 , diluted 1:4,000; Cell Signaling, MA, USA) followed with incubation with the IR-dyed secondary goat anti-mouse immunoglobulin G antibody (Ref: 926-68,020, diluted 1:20,000; LI-COR, NE, USA). For IR detection, in both cases, the membrane was scanned in a Odyssey ${ }^{\mathrm{TM}}$ infrared imaging system (LI-COR, NE, USA), and the bands were detected, identified and quantified using the analysis software provided. The values of cell death-inducing DFFAlike effector (CIDEA) protein in each sample were normalized with the respective values of $\beta$-actin, used as protein of reference.

\section{Statistical analysis}

All data are expressed as the mean \pm S.E.M. Three-way ANOVA was used to determine the existence of effects of gender (S), treatment (T) and diet (D). Two-way ANOVA was used to assess differences by early treatment ( $\mathrm{L}$ vs. C) and diet in adulthood (HF vs. $\mathrm{CH}$ ) in males and females, separately. Analysis by Student's $t$ test was used to test differences between paired groups of the same gender differing in one single condition (for example, C-HC vs. $\mathrm{L}-\mathrm{HC}$ in females). Threshold of significance was defined at $p<0.05$. The analyses were performed with SPSS for Windows (SPSS, Chicago, IL).

\section{Results}

Males show higher levels of expression of brite markers than females in inguinal adipose tissue

Expression of markers associated with brown/brite adipocytes has been found in inguinal adipose tissue in both adult male and females. Interestingly, different expression pattern, mainly related to gender, was observed within the biomarkers selected (Fig. 2). Minor effects of early dietary treatment and diet composition in adult life were shown.

Cell death-inducing DFFA-like effector (CIDEA) is a structural brown adipocyte gene also present in brite cells. CIDEA expression was higher in males than females ( $\mathrm{S}$, $p=0.000)$, and a dietary effect $(\mathrm{D}, p=0.031)$ was also observed, mainly associated with higher expression in HFfed animals. Furthermore, Leu-treated females showed higher CIDEA values in comparison with the respective control groups ( $\mathrm{T}, p=0.019)$. CIDEA protein levels were also determined and confirmed the presence of lower levels in females $(\mathrm{S}, p=0.007)$, whereas the diet and Leutreatment observed on RNA expression were counteracted at protein level (Fig. 2).

T-box15 (Tbx15) is another established gene as a brown/brite adipocyte marker. Tbx 15 was detected in both males and females; however, its high variability in expression indicated that it was not sensible to the variables analysed. UCP1, the canonical marker of BAT, could not be detected in a consistent manner in all samples either at the level of mRNA or protein (data not shown). Similar findings were obtained concerning messenger for PR domain containing 16 (PRDM16) a transcriptional coregulator that controls the development of classical brown adipocytes.

Homeobox C9 (HOXC9) and short stature homeobox 2 (SHOX2) genes have been characterized as brite adipocytes gene markers. Concerning their expression, no significant differences were shown associated either to diet or treatment. However, both genes showed higher levels of expression in males than in females under all conditions studied ( $\mathrm{S}, p=0.000$ and $p=0.001$, respectively).

Males show higher levels of expression of genes than females in inguinal adipose tissue

We have further characterized inguinal gene expression in order to get insight into the metabolic adaptations and potential influence of brite cells in the inguinal depot. Most of the genes showed a clear gender influence, presenting higher expression in males than females as observed with brown/brite markers. Expression pattern of a few genes could be associated with early dietary treatment and only fatty acid synthase (FASN) to current dietary feeding (Fig. 3).

Gene expression of regulatory proteins secreted by adipocytes like leptin (Lep), resistin (RETN) and adiponectin (AdipoQ) were higher in males than in females ( $\mathrm{S}$, $p=0.000, p=0.000$ and $p=0.003$, respectively). In addition, influence of early Leu-treatment (T, $p=0.006)$ was associated with higher expression of leptin in females, and post hoc analysis indicated that L-HF group showed higher levels in comparison with C-HF females $(p=0,001)$.

Managing of triglycerides/fatty acids by adipose triglyceride lipase (ATGL) and lipoprotein lipase (LPL) was also higher in males than females $(\mathrm{S}, p=0.001$ and $p=0.0000$, respectively), and this pattern was also found in the expression of other genes dealing with fatty acid 
CIDEA

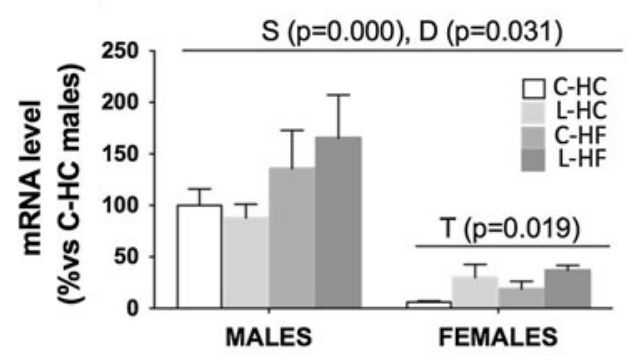

HOXC9

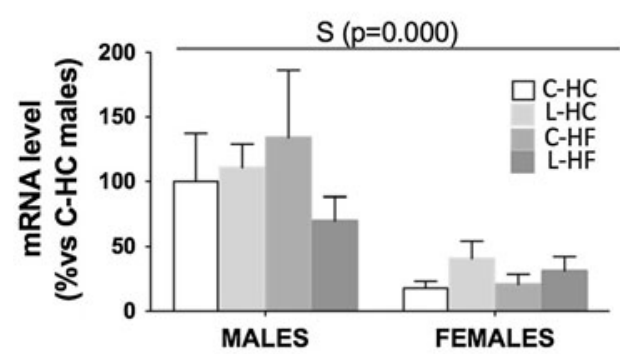

TBX15

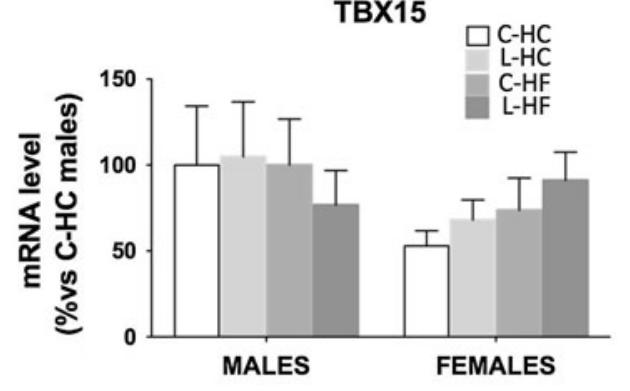

SHOX2

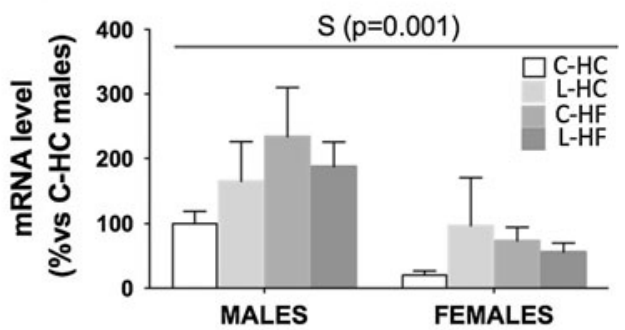

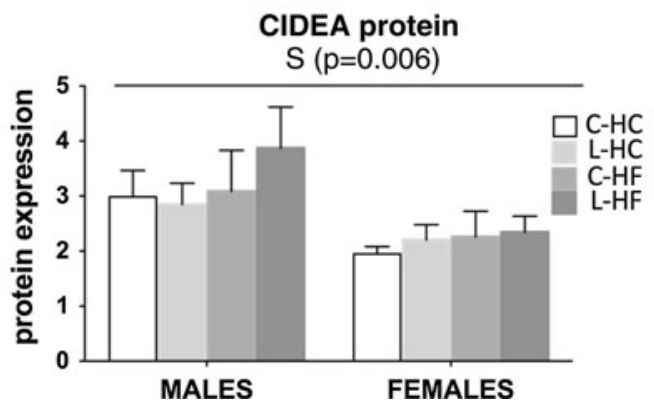

Fig. 2 mRNA expression of brite-associated genes and CIDEA protein levels in inguinal adipose tissue of 9-month-old rats (males and females) fed with a $\mathrm{HF}$ or $\mathrm{HC}$ diet. $\mathrm{L}$ and $\mathrm{C}$ make reference to early dietary treatment that was either leucine supplemented diet (L) or control diet (C). GDI expression was used as housekeeping gene. After assuming comparable levels of expression between males and females, all data are expressed as a percentage of male control animals under $\mathrm{HC}$ diet (C-HC group). CIDEA protein levels have been referenced to $\beta$-actin in the respective samples. Results are mean \pm S.E.M $(n=5-6)$. Effect of sex (S), diet (D) or treatment
(T) was assessed by three/two way ANOVA, horizontal bar details the groups involved in the analysis and $p$ value is indicated. Student's $t$ test was followed for further comparison of groups that differ in one single condition in order to analyse the effect of diet (*) and of leucine treatment (\#), and the $p$ values found statistical significant are indicated in the text. Threshold of significance was set at $p<0.05$ for all analysis. Cell death-inducing DFFA-like effector A (CIDEA), T-box 15 (TBx15), homeobox C9 (HOXC9), short stature homeobox 2 (SHOX2)

receptor gamma 2 (PPAR $\gamma 2)$ were also higher in males than in females ( $\mathrm{S}, p=0.000$ and $p=0.000$, respectively) and reflected the impact of early dietary treatment; PPAR $\gamma 2$ expression was higher in Leu-treated animals (T, $p=0.006)$, and separated gender analysis indicated that the effect was more pronounced in males $(\mathrm{T}, p=0,025)$ and particularly in those under a high-fat diet (L-HF males respect to $\mathrm{C}-\mathrm{HF}, p=0,027)$. In contrast, SREBP1c expression showed the impact of early Leu-treatment in females ( $\mathrm{T}, p=0.045)$, and particularly in those under the high carbohydrate diet (L-HC females versus C-HC, $p=0,026)$. Regarding uncoupling protein, expression of 

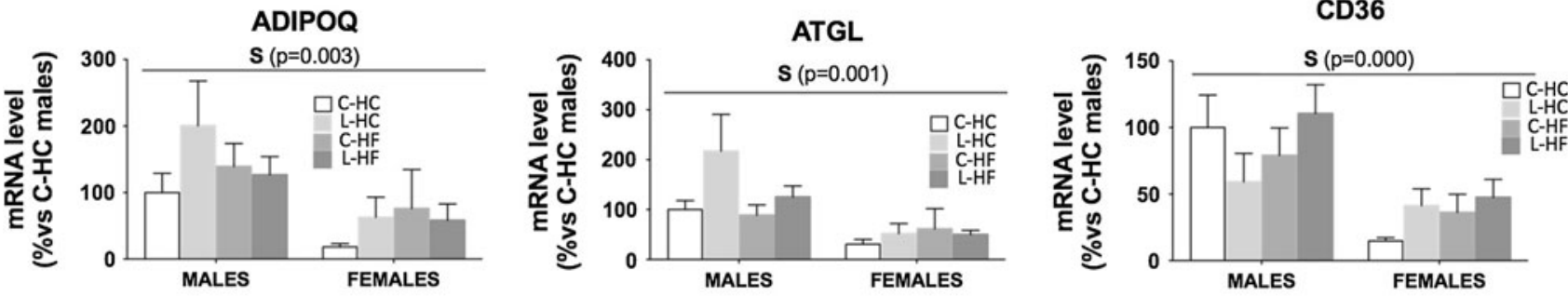

CPT1

FASN
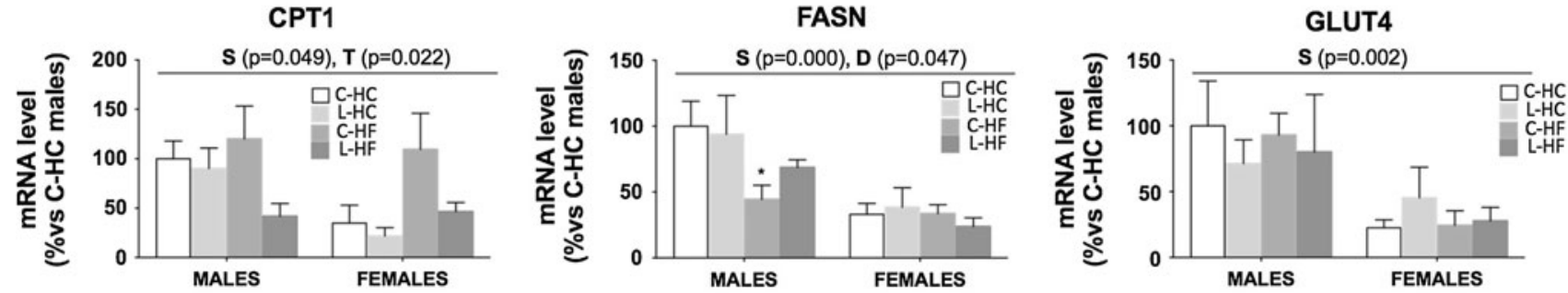

LEP

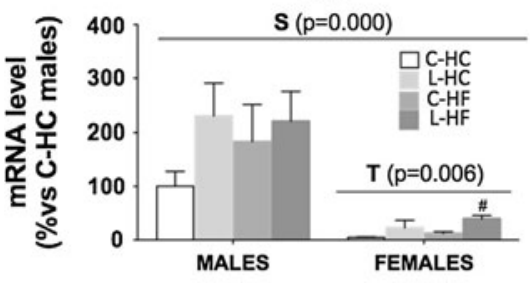

LPL

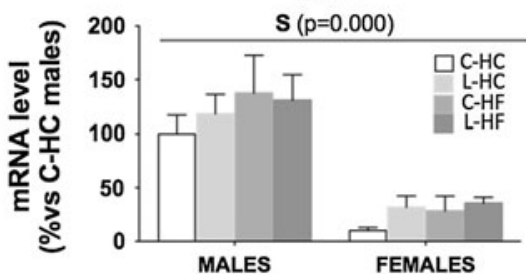

PPAR 2
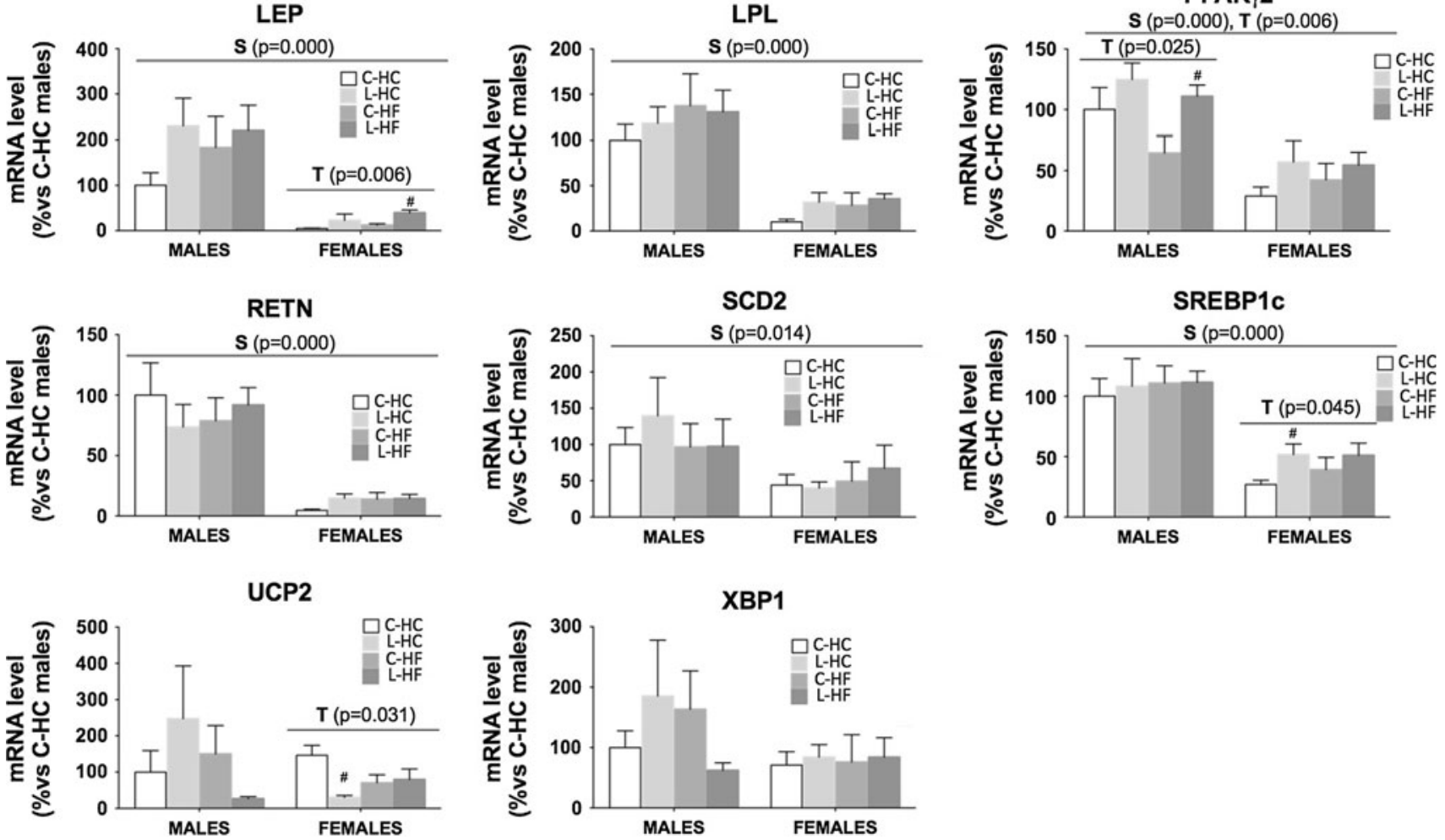

Fig. 3 mRNA expression in inguinal adipose tissue of 9-month-old rats (males and females) fed with a $\mathrm{HF}$ or $\mathrm{HC}$ diet. $\mathrm{L}$ and $\mathrm{C}$ make reference to early dietary treatment that was either leucine supplemented diet (L) or control diet (C). GDI expression was used as housekeeping gene. After assuming comparable levels of expression between males and females, all data are expressed as a percentage of male control animals under $\mathrm{HC}$ diet (C-HC group). Results are mean \pm S.E.M $(n=5-6)$. Effect of sex (S), diet (D) or treatment (T) was assessed by three/two way ANOVA, horizontal bar details the groups involved in the analysis and p value is specified. Student's $t$ test was followed for further comparison of groups that differ in one

single condition in order to analyse the effect of diet $(*)$ and of leucine treatment (\#), and the $p$ values found statistical significant are indicated in the text. Threshold of significance was set at $p<0.05$ for all analysis. Adipo $Q$ adiponectin, $A T G L$ adipose triglyceride lipase, $C D 36$ cluster of differentiation $36, C P T 1$ carnitine palmitoyltransferase $1 \mathrm{~b}$ muscle isoform, FASN fatty acid synthase, GLUT4 facilitated glucose transporter $4, L E P$ leptin, $L P L$ lipoprotein lipase, $P P A R \gamma 2$ peroxisome proliferator activated receptor gamma $2, R E T N$ resistin, SCD2 stearoyl-Coenzyme A desaturase 2, SREBP1c sterol regulatory element binding transcription factor $1 \mathrm{c}, U C P 2$ uncoupling protein 2, XBP1 X-box binding protein 1 
UCP2 was decreased by early Leu-treatment in females (T, $p=0.031$ ) and particularly in the group under the $\mathrm{HC}$ diet (females L-HC in comparison with $\mathrm{C}-\mathrm{HC}$ ), $p=0.001$ ).

Capacity to transport glucose mediated by GLUT4 showed the same tendency as seen for fatty acid-related genes, being higher in males than in females $(\mathrm{S}$, $p=0.002$ ), and it was not influenced by early Leu-treatment or diet composition in adult life. The marker of macrophage infiltration (CD36) was also higher in males than females $(S, p=0.000)$ in accordance with the rest of the genes analysed. Expression of X-box binding protein 1 (XBP1), part of the endoplasmic reticulum (ER) stress response, was not different between groups.

\section{Discussion}

It is known that gender differences in obesity originate mainly from hormonal and metabolic differences between sexes. Recently, a series of proteomic analysis have revealed some of the gender-specific characteristics of the proteome profile in BAT (Choi et al. 2011) and WAT depots (Mukherjee et al. 2012). Gender dimorphism is present at the level of adipose protein expression and affects a reduced number of proteins (between 25 and 46 depending on the source of the depot) (Mukherjee et al. 2012). In accordance, previous data from our lab also show lower transcriptomic expression in females compared to male rats. Interestingly, differences between sexes are more marked in inguinal WAT (Priego et al. 2008). Subcutaneous white adipose depots have a higher propensity towards expression of brite markers compared to the visceral depots (Wu et al. 2012). However, no data are available concerning gender differences in the potential of the inguinal adipose tissue to express brite-associated genes. Our data show that although both genders express and therefore may induce, brite genes in inguinal adipose tissue, males expressed higher levels of CIDEA, HOXC9 and SHOX2, and the same trend was detected for Tbx15 (Fig. 2). Furthermore, CIDEA protein levels were also higher in males than females, highlighting that the gender differences in brite potential may spread to protein levels.

The pattern seen in the expression of brite-associated genes was a reflection of the metabolic potential of the tissue in a gender-related manner. Therefore, in comparison with females, males presented higher expression of adipocyte-associated regulatory proteins such as leptin, adiponectin and resistin; higher handling capacity of lipids/ fatty acids by LPL and ATGL; and their processing by FASN, CPT1 and SCD2. In addition, lipid regulatory factors such as SREBP1c and PPAR $\gamma 2$ were also expressed at higher level in males than in females (Fig. 3). All together, the data indicate that female rats have lower lipid metabolic capacity in inguinal adipose tissue in comparison with males. This pattern, shared by brite-associated genes too, may suggest a lower browning capacity in white adipose tissue of female rats in comparison with males.

Another question raised in the present study was the relevance of dietary impact in the expression of brite genes in a gender-specific manner. We were interested in analysing the impact of diet composition in adult life but also in identifying effects of early dietary manipulation on brite expression in rats. Diets with a high content of fat (HF) or carbohydrate (HC) were selected in adult life as tools to check the potential of brite induction in inguinal adipose. No data are available on the performance of inguinal WAT on brite induction by dietary manipulation in rats. Most of the studies have been performed in mice, and the general view is that HF feeding may increase thermogenesis in BAT but reduces the brite potential in WAT. In this context, brite adipocytes would be displaced by white adipocytes to store fat in a time of surplus (Bonet et al. 2013). However, differences between species may occur as increased expression of UCP1 mRNA by HF feeding has been found in abdominal fat in female rats (Margareto et al. 2001) and in retroperitoneal adipose tissue in male hypertensive rats (Hojna et al. 2012). We were unable to detect UCP1 either at the level of mRNA or protein, and minor impact of HF diet in adult life was observed in the rest of the genes studies. CIDEA was the only brite gene affected by the dietary treatment, showing increased expression in HF-fed animals in comparison with the HC diet, a pattern shared by both genders. However, these differences were buffered at CIDEA protein level. The role of CIDEA has been associated with lipid droplet enlargement and appears broadly expressed in most of the multilocular cells. Furthermore, the presence of CIDEA positive with UCP1 negative multilocular adipocytes in WAT depots in cold acclimated mice has been proposed as an early stage on adipocyte transdifferentiation (Barneda et al. 2013). Although this is a possibility that cannot be ruled out in our experimental setup, it would need further investigation.

In addition, results provided evidence for the role of early dietary manipulation, which was able to compromise the metabolic fate of white and brite adipocytes later in adult life. We have used a model of maternal dietary leucine supplementation during lactation (López et al. 2010). In this model, nursing dams show a healthier profile of body composition, without compromising the growth and development of the progeny by a mechanism that would involve lower expression of orexigenic neuropeptides in hypothalamus (López et al. 2010). Data indicated that early leucine supplementation programmed higher expression of CIDEA, which could be regulated by the induction of SREBP and was accompanied by lower UPC2 expression, particularly in females. Interestingly, post-transcriptional 
mechanisms may be acting on CIDEA regulation, because CIDEA protein levels were homogeneous in all the groups of females, irrespective of diet and early leucine treatment.

In addition, early leucine supplementation was associated with higher expression of $\operatorname{PPAR} \gamma$ together with decreased CPT1 in both genders. In adipocytes, CIDEA seems to mediate SREBP-dependent lipid accumulation under the control of PPAR $\gamma$ (Puri et al. 2008). Our results fit with this model and altogether seem to indicate that the main effect of early leucine supplementation was the promotion of lipid storage potential, particularly in female offspring, which also show higher expression of leptin. Although the exact role of these adaptations needs further comprehensive analysis, dietary leucine supplementation at early age programmed inguinal adipose tissue in a gender specific manner.

Taken together, this study demonstrated that the level of expression of genes related to browning process in adipose tissue is gender dependent, male rats presenting higher levels than females. This pattern is similar to that found for most of genes associated with adipocyte metabolism and analysed in the present study. Furthermore, our data show minor impact of diet composition in adult life in the expression pattern of brite-associated genes, whereas influence of early dietary supplementation to maternal diet seems to have higher relevance. This knowledge may provide bases for specific evidence-based interventions and therefore allowing for more focused prevention and/or treatment of obesity.

Acknowledgments This work was supported by the Grant AGL2012-33692 and the EU-funded project DIABAT (HEALTH-F22011-278373). Our group receives financial support from Instituto de Salud Carlos III, Centro de Investigación Biomédica en Red Fisiopatología de la Obesidad y Nutrición, CIBERobn. Authors belong to the Nutrigenomics-group, awarded as "Group of Excellence" of CAIB and supported by "Direcció General d'Universitats, Recerca i Transferència del Coneixement" of Regional Government (CAIB) and FEDER funds (EU)

Conflict of interest The authors declare that they have no conflict of interest. Authors declare that they have full control of all primary data and agree to allow the journal to review their data if requested. The funders had no role in the study design, data collection and analysis, decision to publish, or preparation of the manuscript.

\section{References}

Barbatelli G, Murano I, Madsen L, Hao Q, Jimenez M, Kristiansen K, Giacobino JP, De Matteis R, Cinti S (2010) The emergence of cold-induced brown adipocytes in mouse white fat depots is determined predominantly by white to brown adipocyte transdifferentiation. Am J Physiol Endocrinol Metab 298:E1244-E1253
Barneda D, Frontini A, Cinti S, Christian M (2013) Dynamic changes in lipid droplet-associated proteins in the "browning" of white adipose tissues. Biochim Biophys Acta 1831:924-933

Bonet ML, Oliver P, Palou A (2013) Pharmacological and nutritional agents promoting browning of white adipose tissue. Biochim Biophys Acta 1831:969-985

Choi DK, Oh TS, Choi JW, Mukherjee R, Wang X, Liu H, Yun JW (2011) Gender difference in proteome of brown adipose tissues between male and female rats exposed to a high fat diet. Cell Physiol Biochem 28:933-948

Cinti S (2005) The adipose organ. Prostaglandins Leukot Essent Fatty Acids 73:9-15

Cousin B, Cinti S, Morroni M, Raimbault S, Ricquier D, Pénicaud L, Casteilla L (1992) Occurrence of brown adipocytes in rat white adipose tissue: molecular and morphological characterization. J Cell Sci 103(Pt 4):931-942

Distel E, Penot G, Cadoudal T, Balguy I, Durant S, Benelli C (2012) Early induction of a brown-like phenotype by rosiglitazone in the epicardial adipose tissue of fatty Zucker rats. Biochimie 94:1660-1667

Frontini A, Vitali A, Perugini J, Murano I, Romiti C, Ricquier D, Guerrieri M, Cinti S (2013) White-to-brown transdifferentiation of omental adipocytes in patients affected by pheochromocytoma. Biochim Biophys Acta 1831:950-959

Ghorbani M, Himms-Hagen J (1997) Appearance of brown adipocytes in white adipose tissue during CL 316,243-induced reversal of obesity and diabetes in Zucker fa/fa rats. Int $\mathrm{J}$ Obes Relat Metab Disord 21:465-475

Hojna S, Jordan MD, Kollias H, Pausova Z (2012) High-fat diet induces emergence of brown-like adipocytes in white adipose tissue of spontaneously hypertensive rats. Hypertens Res 35:279-286

Karastergiou K, Smith SR, Greenberg AS, Fried SK (2012) Sex differences in human adipose tissues - the biology of pear shape. Biol Sex Differ 3:13

Lasar D, Julius A, Fromme T, Klingenspor M (2013) Browning attenuates murine white adipose tissue expansion during postnatal development. Biochim Biophys Acta 1831:960-968

Livak KJ, Schmittgen TD (2001) Analysis of relative gene expression data using real-time quantitative PCR and the 2(-Delta Delta C(T) ) Method. Methods 25:402-408

López N, Sánchez J, Picó C, Palou A, Serra F (2010) Dietary Lleucine supplementation of lactating rats results in a tendency to increase lean/fat ratio associated to lower orexigenic neuropeptide expression in hypothalamus. Peptides 31:1361-1367

Margareto J, Larrarte E, Marti A, Martinez JA (2001) Up-regulation of a thermogenesis-related gene (UCP1) and down-regulation of PPARgamma and aP2 genes in adipose tissue: possible features of the antiobesity effects of a beta3-adrenergic agonist. Biochem Pharmacol 61:1471-1478

Mukherjee R, Choi JW, Choi DK, Oh TS, Liu H, Yun JW (2012) Gender-dependent protein expression in white adipose tissues of lean and obese rats fed a high fat diet. Cell Physiol Biochem 29:617-634

Nedergaard J, Bengtsson T, Cannon B (2007) Unexpected evidence for active brown adipose tissue in adult humans. Am J Physiol Endocrinol Metab 293:E444-E452

Priego T, Sánchez J, Picó C, Palou A (2008) Sex-differential expression of metabolism-related genes in response to a high-fat diet. Obesity (Silver Spring) 16:819-826

Puri V, Ranjit S, Konda S, Nicoloro SM, Straubhaar J, Chawla A, Chouinard M, Lin C, Burkart A, Corvera S, Perugini RA, Czech MP (2008) Cidea is associated with lipid droplets and insulin sensitivity in humans. Proc Natl Acad Sci USA 105:7833-7838

Richard D, Picard F (2011) Brown fat biology and thermogenesis. Front Biosci 16:1233-1260 
Saely CH, Geiger K, Drexel H (2012) Brown versus white adipose tissue: a mini-review. Gerontology 58:15-23

Saito M (2013) Brown adipose tissue as a regulator of energy expenditure and body fat in humans. Diabetes Metab J 37:22-29

Sharp LZ, Shinoda K, Ohno H, Scheel DW, Tomoda E, Ruiz L, Hu H, Wang L, Pavlova Z, Gilsanz V, Kajimura S (2012) Human BAT possesses molecular signatures that resemble beige/brite cells. PLoS One 7:e49452

Virtanen KA, Lidell ME, Orava J, Heglind M, Westergren R, Niemi T, Taittonen M, Laine J, Savisto NJ, Enerbäck S, Nuutila P
(2009) Functional brown adipose tissue in healthy adults. N Engl J Med 360:1518-1525

Wu J, Boström P, Sparks LM, Ye L, Choi JH, Giang AH, Khandekar M, Virtanen KA, Nuutila P, Schaart G, Huang K, Tu H, van Marken Lichtenbelt WD, Hoeks J, Enerbäck S, Schrauwen P, Spiegelman BM (2012) Beige adipocytes are a distinct type of thermogenic fat cell in mouse and human. Cell 150:366-376 